\title{
O qim como recurso no ensino básico do norte de Portugal: Estudo de boas práticas
}

\author{
Joaquim Jacinto Escola ${ }^{a}$, Natália Lopes Moura ${ }^{b}$ y Manuela Raposo-Rivas ${ }^{c}$ \\ Rebut: 29/05/2015 Acceptat: 03/11/2015
}

\section{Resumo}

A emergente sociedade do conhecimento veio desferir novos desafios ao contexto educativo e intimar a transformação das práticas dos professores para uma resposta mais assertiva e resiliente face às necessidades da integração de novas tecnologias na sala de aula.

Considerando que não vivemos alheios a estas exigências da sociedade atual e sensíveis aos esforços do Ministério da Educação Português para dotar as escolas com tecnologias, tínhamos o objetivo de conhecer a realidade do Quadro Interativo Multimédia (QIM) nas escolas portuguesas do Norte do país; estudar o seu contributo no ensino e aprendizagem e desenhar um modelo metodológico adequado didaticamente às suas caraterísticas interativas, que fosse um acompanhamento de excelência para os professores enfrentarem esta tecnologia e conseguir a sua integração na prática letiva, demonstrando a importância deste recurso como ferramenta cognitiva.

Seguimos uma metodologia de natureza mista: quantitativa, exploratória e descritiva quanto ao uso do QIM nas escolas de Viana do Castelo, Braga, Porto, Vila Real e Bragança, e qualitativa no que diz respeito ao estudo de metodologias e boas práticas de utilização. O modelo obtido, pretende ser um instrumento para guiar os professores numa escola voltada para a inclusão digital e, sobretudo, focada na aprendizagem e formação do aluno.

\footnotetext{
a Universidade de Trás-os-Montes e Alto Douro - Portugal

b Universidade de Trás-os-Montes e Alto Douro - Portugal

c Universidade de Vigo - España
} 
Palavras-chave: Quadro Interativo Multimédia, Tecnologias de Informação e Comunicação, Ensino Básico, Boas Práticas.

\section{Iwb as a resource in basic education of northern Portugal: Study of best practices}

\section{Abstract}

The emerging knowledge society places new challenges on education systems and challenges teachers to change their practice methods for a more forceful and resilient response to the need of integrating new technologies in the classroom.

Considering that we are not unaware of modern society demands and that we are sensitive to the Portuguese Education Ministry efforts to equip schools with new technology, our aim was to get to know the reality of the Interactive Whiteboard (IWB) in Portuguese schools of northern; to study its contribution to teaching and learning; and to develop a methodological model adjusted to its interactive features that can be a tool par excellence that teachers use to face the demands of this technology; and to manage to integrate it in the classroom practice while proving its importance as a cognitive tool.

A mixed-model method was used: quantitative, exploratory and descriptive in relation to the use of the IWB in the Viana do Castelo, Braga, Porto, Vila Real and Bragança schools; and qualitative in terms of the study of methodologies and best practice of use.

This model intends to be a tool to guide teachers in a digital inclusion-oriented school that is focused mainly on pupils' learning and training.

Keywords: Interactive Whiteboard, Information and communication Technologies, Elementary Education, Best Practice.

\section{Introdução}

É incontornável e não é possível retroceder: as Tecnologias da Informação e da Comunicação (TIC) estão por todo o lado e fazem parte do nosso quotidiano. Como afirma Ilharco (2004:9), "nunca na História a atividade humana dependeu tanto da tecnologia" porque se ouve o eco das palavras de Paulo Freire (1996) e se percebe as suas possibilidades. Assistimos a uma época em constante mudança tecnológica que exige uma renovação e adaptação às novas realidades pelas enormes possibilidades que elas acarretam. Perante este fenómeno evolutivo das tecnologias a escola não pode ficar indiferente deixando que a velocidade do tempo tecnológico a ultrapasse 
ou, então, a invada e a seduza de forma acrítica pelo seu brilho nem sempre genuíno. Efetivamente, a escola em geral e, os professores em particular, deixaram de ser os guardiães sem crédito de um cofre de conhecimento há muito esventrado pela vertigem do progresso das tecnologias.

Como consequência dessa sociedade cada vez mais tecnológica tem-se apostado em Portugal na modernização da escola, essencialmente, através do Plano Tecnológico da Educação (PTE, 2007), que pretendia tornar real a integração das TIC no contexto educativo e desejava desencadear mudanças no processo de ensino e de aprendizagem. Esse programa de modernização tecnológica das escolas portuguesas apostou na substituição dos velhos quadros negros por novos recursos tecnológicos, nomeadamente o QIM.

Assim, não podemos permanecer agarrados às tradições pois, atualmente, a sociedade exige que haja mudanças. Na sociedade atual, o "quadro negro", o giz e o apagador não podem continuar a ser os únicos símbolos da escola. Marcaram um

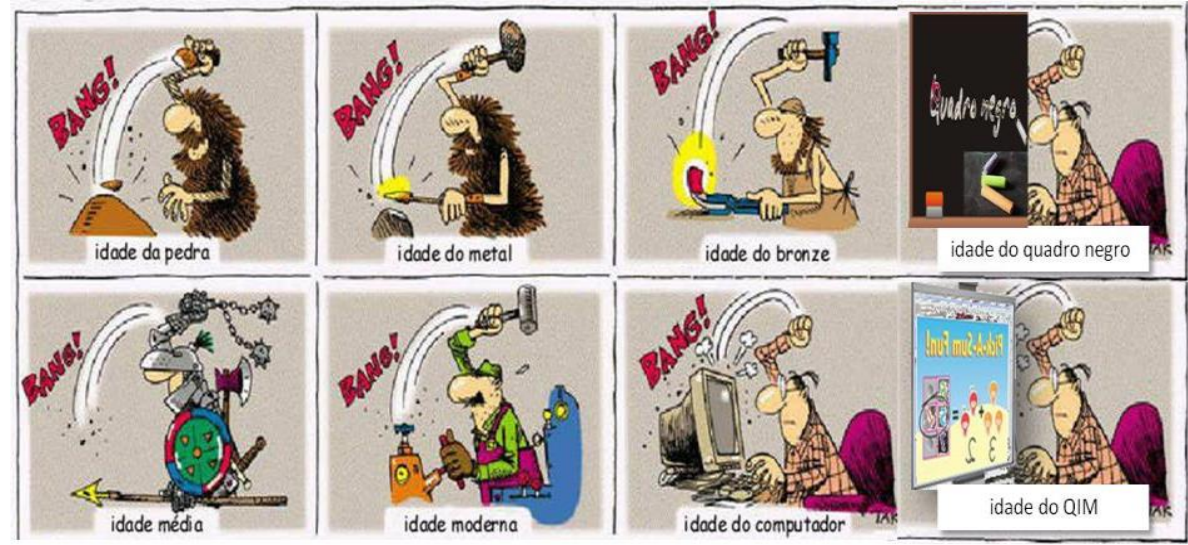

período na história da educação, como outrora outros instrumentos/recursos se distinguiram na sociedade/escola e quando parecia que tudo estava inventado, aparecem os quadros interativos levando-nos para a "Era do QIM" (Figura I).

Figura I: Instrumentos/recursos que marcam a sociedade/escola (Lopes, Escola e Raposo, 2013)

Mas de que servirá o QIM em contexto educativo se o professor não responder ao desafio da inovação e se os alunos não o usarem? Sabemos que, embora já se façam presentes nas salas de aula, ainda não possuem a centralidade do velho quadronegro. Por isso, o espírito deste artigo, resultado do estudo realizado durante o curso de doutoramento em ciências da educação, é expor a realidade vigente nas escolas do ensino básico no que diz respeito ao QIM, no Norte de Portugal. Centrámo-nos no uso e abusos do QIM no ensino/aprendizagem, quisemos verificar in loco como se processa a sua utilização, quais as dificuldades enfrentadas pelos docentes nessa mesma utilização e a forma como foram, ou não, ultrapassadas as reticências iniciais. 
Além disso, definimos um modelo para o seu uso, de modo a que haja alterações quer ao nível da centralidade do ensino, quer ao nível dos métodos, dos processos, dos conteúdos e dos próprios ambientes de aprendizagem.

\section{A realidade do estudo: contextualização}

Neste oceano emaranhado de tecnologia, o QIM traz para a sala de aula uma nova dimensão tecnológica que pode envolver os alunos, num ambiente de aprendizagem mais criativo, interativo e sobretudo dinâmico. Passaremos das aulas relativamente estáticas, onde os alunos tinham um papel de observadores e consumidores de conteúdos, para a "era" do som, movimento e imagem, com uma crescente participação dos alunos.

Cremos que o QIM poderá dar frutos, francamente positivos, no processo de ensino/aprendizagem. Para além do fator novidade, interatividade partilhada, entre outros, oferece ainda um conjunto de ferramentas que, de certa forma, procuram facilitar e enriquecer diversas tarefas em contexto de sala de aula. Sendo o sucesso escolar dos alunos a pretensão de qualquer professor e mostrando a investigação que a utilização das TIC para fins pedagógicos é um fator de motivação e de inovação educativa, consideramos que o QIM é uma ferramenta que pode ajudar os professores a criar espaços de aprendizagem entusiasmantes e seduzir crianças e jovens de todas as idades e capacidades.

É necessário que os professores vejam no uso do QIM um aliado na árdua tarefa de motivar e despertar para o caminho do conhecimento. Rentabilizar o seu uso parecenos fundamental para o desenvolvimento de estratégias de ensino e aprendizagem capazes de motivar os alunos, que mergulham diariamente nas lides tecnológicas. A forma atrativa como permitem a apresentação da informação e as potencialidades interativas que lhe são reconhecidas devem ser canalizadas para um ensino aberto à partilha de ideias, à colaboração dos diferentes intervenientes e consequente construção do conhecimento.

Muito se tem ouvido falar sobre a utilização do QIM na escola. A aprendizagem tradicional começa a ceder, em prol da aprendizagem centrada nos hipermédia que incluem o QIM (imagens e sons associam-se a textos e a outros sons e imagens). O ensino caminha para um estado de construção e descoberta, no qual o professor passa de transmissor a facilitador da aprendizagem e a mera absorção de conteúdos programáticos dará lugar à crítica reflexiva de informação. Assim, é dada ao aluno a possibilidade de ser ele próprio a construir a sua aprendizagem, permitindo que se questione, atue e observe o produto da sua ação.

Portanto, estudar o "mundo" do QIM pareceu-nos um percurso aliciante porque havia um longo caminho para trilhar neste horizonte uma vez que, seria o único estudo, até à presente data, que dedicaria a sua atenção à perspetiva dos diretores e à dos professores de todo o ensino básico na utilização do QIM (Lopes, Escola, Raposo, 2014). A maioria dos estudos realizados neste campo ou versou a sua 
atenção na perspetiva aos professores (Antunes, 2008; Batista, 2009; Corrente, 2009; Folhas, 2010; Ferreira, 2011; Esteves e Lencastre, 2013; Vasconcelos e Moreira, 2013) ou, se interessaram pela perspetiva dos professores e dos alunos (Pereira, 2008; Fernandes, 2009; Spínola, 2009) ou apenas na perspetiva dos alunos (Ferreira, 2009; Marques, 2009; Ferreira, 2010; António, 2011; Martins, 2012).

A reflexão impõe-se, como particularmente importante, para que exista uma lucidez de análise face à invasão do QIM na vida escolar. Além disso, acreditamos que com a sua integração no contexto educativo podemos estar perante a oportunidade ímpar de diminuir a fratura digital e de facilitar uma articulação eficaz entre os digital immigrants e os digital natives (Prensky, 2009).

Considerámos, pois, fundamental perceber se o investimento que o Ministério da Educação de Portugal tem feito neste recurso seria vantajoso para o ensino, uma vez que segundo o que observávamos na nossa prática docente, o QIM ainda não era utilizado e aqueles que o utilizavam faziam-no com pouca frequência. Questionávamo-nos sobre as razões que levariam os professores a não aproveitar a totalidade das suas potencialidades.

Assim, germinou-se a pretensão de desenhar um modelo metodológico (adequado didaticamente às caraterísticas interativas para uso do quadro interativo a partir da compilação de boas práticas com o QIM em diferentes áreas curriculares) porque pretendíamos demonstrar a importância deste recurso como ferramenta cognitiva. Ambicionávamos apresentar um modelo que definisse uma boa utilização do QIM para desenvolver um repertório compartilhado de ferramentas, rotinas, histórias e conceitos.

\section{Caracterização geral do estudo}

O desenvolvimento deste trabalho baseou-se na recolha e interpretação de dados junto de diretores e professores de um grupo de escolas do Norte de Portugal que permitiu conhecer, com um grau de detalhe considerável, a realidade estudada. Posteriormente desenhamos um modelo metodológico para uso do QIM no processo de ensino/aprendizagem (Autor, 2015), tendo em conta atividades de sucesso com este recurso, apreendidas ao longo de todo o trabalho de investigação.

\subsection{Objetivos da investigação}

Para conseguir responder à questão central Qual a realidade do QIM nas escolas do Ensino Básico no Norte de Portugal: presença, usos e metodologias? e às questões adjacentes, foram delineados os seguintes objetivos:

- Fazer o levantamento dos agrupamentos apetrechados com QIM (quantidade/ grau de apetrechamento/disponibilidade) e averiguar em que área geográfica/ciclo de escolaridade existe maior quantidade. 
- Perceber se os professores têm preferência por algum QIM e qual a marca predominante no agrupamento, o critério usado para a escolha e as razões que conduziram à sua aquisição.

- Aferir se os agrupamentos contemplam e promovem o uso do QIM junto da comunidade educativa.

- Verificar se os professores usam ou não o QIM, em que área geográfica, o ciclo de escolaridade e a área disciplinar / disciplina em que mais usam, como o usam, com que justificação, finalidade e frequência.

- Conferir se os diretores usam ou não o QIM, com que justificação e em que ocasião segundo a área geográfica.

- Aferir se fatores como o ano de escolaridade, a disciplina ou a área disciplinar, a idade do professor, influenciam a utilização do QIM.

- Compreender as potencialidades da utilização do QIM e perceber como melhorar as práticas pedagógicas e as aprendizagens dos alunos.

- Verificar as mudanças que ocorrem no contexto de sala de aula com o uso do QIM quanto à motivação, atenção, empenho, comunicação, interação, trabalho em equipa, ensino e aprendizagem.

- Perceber a perceção dos professores sobre a reação dos alunos quando se usa o QIM.

- $\quad$ Apurar as dificuldades dos professores e diretores no uso do QIM.

- Aferir a competência/domínio, formação e as necessidades de formação dos docentes para o uso do QIM.

- Identificar e analisar Boas Práticas no uso do QIM nas diferentes áreas curriculares.

- Desenhar um modelo metodológico de uso do QIM.

\subsection{Opções metodológicas}

Para compreender o caminho seguido traçámos um desenho metodológico (Figura II) que esclarece os métodos, as técnicas e a amostra que seguimos de modo a responder às questões e aos objetivos da investigação. Nessa figura percebe-se que o nosso modelo de investigação foi misto e à medida que se recolheram e analisaram os dados, apresentou características de um estudo de caso.

A nossa investigação ficou valorizada pela junção dos dois métodos, uma vez que partilhamos do pensamento de Flick (2004:55) ao considerar que a "investigação qualitativa e a quantitativa não estão em campos opostos que não se devam combinar". Considerando que recolhemos dados para verificar o cosmos do QIM, optamos pelo método quantitativo já que é um método baseado na recolha de 
dados observáveis e quantificáveis, na observação de factos, de acontecimentos e de fenómenos que ocorrem independentemente do investigador (Fortin, 1999). Dessa forma, o nosso estudo é descritivo-exploratório, pois tinha por objetivo conhecer, descrever e compreender fenómenos, e baseia-se na observação, que se realiza no ambiente natural, usando técnicas quantitativas e qualitativas de recolha de dados. Fizemos uma descrição densa e detalhada da realidade do QIM e os dados procuraram esclarecer a realidade do QIM no Norte de Portugal.

Portanto, a nossa caminhada contemplou dois momentos distintos mas complementares. Num primeiro momento, foi feito o estudo quantitativo do QIM nas escolas do Norte de Portugal. Nessa fase, o instrumento de recolha de dados foi a aplicação de um inquérito por questionário aos diretores e professores. Após essa análise, a nossa investigação prosseguiu com a realização de entrevistas e com a formação e posterior observação, a um grupo específico de professores em contexto de sala de aula, analisando as suas práticas com o QIM através da observação direta. Neste segundo momento, em que a investigação é de tipo qualitativo, a diversidade das técnicas de recolha de dados é importante para a chamada triangulação de dados, processo que confere ao estudo um elevado grau de validade.

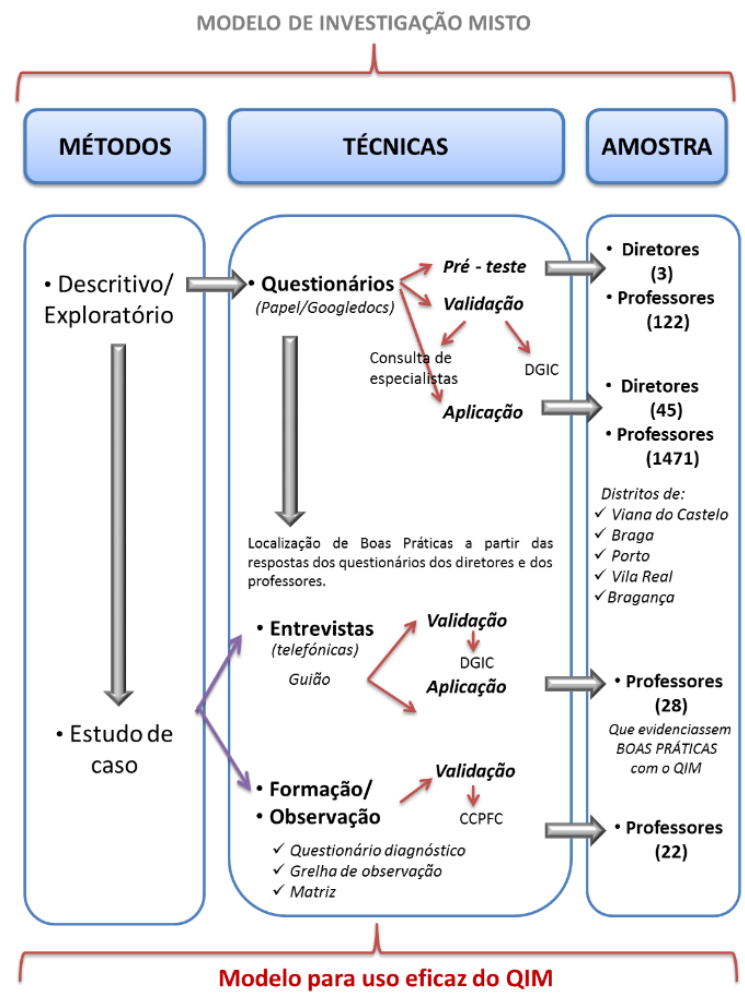

Figura II: Desenho Metodológico (Autor, 2015:175) 


\subsection{Caracterização da população/amostra}

Os participantes deste estudo foram os professores do $1 .^{\circ}, 2^{\circ}$ e $3 .^{\circ}$ ciclos do Ensino Básico dos cinco distritos do norte de Portugal (Viana do Castelo, Braga, Porto, Bragança e Vila Real) e, os respetivos diretores por considerarmos que um diretor inovador e utilizador das referidas TIC é, muitas vezes, o pilar que sustenta a inovação e a criatividade na escola. O exemplo é, sem dúvida, o melhor antídoto para o marasmo do "deixa andar". O facto de se escolher os cinco distritos mais a Norte de Portugal permitiu comparar resultados e aferir as diferenças na quantidade e no uso do QIM entre o Litoral e o Interior do Norte do país. Perante os passos seguidos e as decisões tomadas, classificámos a nossa amostra como aleatória por clusters. Os clusters foram escolhidos aleatoriamente $\mathrm{e}$, dentro de cada cluster todos os elementos são selecionados, ou seja, só existe uma etapa de amostragem.

No que diz respeito à amostra dos professores entrevistados, a escolha baseou-se num único critério: ser portador de uma Boa Prática com o QIM, quer fosse o próprio professor a indicar essa realidade com uma resposta clara e correta (aquando do preenchimento do inquérito por questionário) ou, apontado por outro professor que indicasse conhecer uma boa prática e a forma de acedermos a essa Boa Prática.

Os professores que frequentaram a formação no âmbito do QIM foram selecionados de entre todos os que manifestaram estar interessados em frequentar alguma ação de formação em QIM ou indicassem que não o usavam por falta de formação. Por isso, a seleção da amostra dos professores participantes na ação de formação foi feita de forma criteriosa e intencionada.

Portanto, no nosso estudo podemos distinguir entre:

- Amostra convidada: diretores e professores das escolas públicas do ensino básico dos 5 distritos pertencentes ao Norte de Portugal (Viana do Castelo; Braga; Porto; Vila Real e Bragança.

- Amostra participante: 52 diretores e 1482 professores respondentes aos questionários; 28 professores entrevistados e 22 formandos.

- Amostra produtora de dados: diretores/professores que consideramos para tratamento de dados mediante os critérios que definimos (45 diretores; 1471 professores; 28 professores entrevistados e 22 formandos. Perante o número de respostas obtidas dos diretores, considerámos a representatividade por distrito, assegurando um mínimo de $20 \%$, pois considerámos como respostas válidas o dobro do mínimo exigido. Assim, renunciamos 5 respostas no distrito de Bragança, 1 no de Viana do Castelo e 1 no de Vila Real. Relativamente aos professores tivemos de renunciar a representatividade por distrito, porque nos interessava ter maior relevância de respostas e aproximar-nos de uma percentagem mais alta da população. Considerámos portanto os agrupamentos por zona - zona interior e zona litoral. Desse modo, não considerámos para análise as 11 respostas do 
distrito de Vila Real, correspondente a 4 agrupamentos de escolas, nos quais obtivemos menor número de professores respondentes.

\subsection{Técnicas e instrumentos de recolha de dados}

De acordo com o paradigma metodológico assumido, foram mobilizadas várias técnicas e instrumentos de recolha de dados que nos permitiram dar resposta aos objetivos e questões de investigação. Optamos por escolher como técnicas de recolha de dados, a revisão da literatura, a análise documental, os inquéritos (questionários e entrevistas) e a observação para podermos assegurar as diferentes perspetivas dos participantes no estudo e obter várias "dimensões" do mesmo fenómeno.

Procedemos a uma revisão de literatura através de leituras exploratórias focadas, por um lado, no estado da arte do QIM, que permitiu assegurar a qualidade da problematização (Quivy \& Campenhoudt, 2003), e, por outro, na adequada configuração metodológica, pois consideramos essencial a reunião de informação no plano teórico que fundamente as nossas conjeturas. A revisão da literatura cristaliza este processo, porque é "um quadro teórico de referência que sustenta a investigação e lhe oferece credibilidade" (Pardal \& Correia, 1995: 15). A par desta revisão, procedeu-se à análise documental da legislação que suporta o PTE e de certos documentos produzidos pelo Ministério da Educação dado o desafio que apresentam e aos quais o estudo devia permanecer atento.

Os inquéritos por questionários, as entrevistas, a formação ministrada e a observação de aulas serviram para recolher elementos que nos permitissem aprofundar alguns aspetos relacionados quer com as questões em estudo, quer com questões emergentes da análise da informação recolhida por questionário, diversificando as fontes e os pontos de vista. Na análise de dados, como a sua natureza é distinta e obriga a um tratamento diferenciado dos mesmos, privilegiou-se a análise de conteúdo para as questões abertas com a finalidade de as interpretar (Quivy \& Campenhoudt, 2003) e, procedimentos estatísticos para as questões fechadas (Pardal e Correia, 1995). Recorremos ao Nvivo, na sua versão 10.0 para análise qualitativa de dados e ao software Microsoft Excel 2010 para o tratamento dos dados quantitativos e elaboração de gráficos, por se tratar de uma ferramenta adequada, não se revelar significante para o estudo em causa, modelos estatísticos complexos e pelo domínio na utilização da mesma. Recorremos à estatística descritiva para considerar as frequências e as percentagens de resposta.

\subsubsection{Questionários}

A opção pela construção de questionários parece-nos a mais adequada para uma recolha de dados que se pretende objetiva, favorecendo a obtenção de informação quantitativa sobre a qual seja mais fácil aplicar análises estatísticas para analisar as 
respostas. Além disso, é um instrumento que permite abranger um grande número de respondentes num curto espaço de tempo, dispensa a presença do investigador, é um método económico, permite manter o anonimato, pode ser construído com fins específicos e o investigador não influencia no momento de recolha de dados.

Durante a nossa investigação, foram usados vários tipos de inquéritos por questionário, aplicados em diferentes momentos mas com objetivos complementares entre si. Foram desenhados segundo as regras da investigação científica (Tuckman, 2000) e tivemos em conta 3 princípios básicos: princípio da clareza (questões claras e concisas), princípio da coerência e princípio da neutralidade (não formular as questões sob a forma de juízos de valor ou preconceitos).

Estes questionários foram elaborados de raiz, com questões de resposta fechada e aberta atendendo ao público-alvo e aos objetivos concretos. Possuíam seis eixos de análise (caracterização do diretor/professor e do seu meio escolar; equipamento e disponibilidade do QIM; utilização do quadro interativo multimédia; problemas/dificuldades e apoio/auxílio técnico com o $\mathrm{QIM}$; dados relativos à formação em e para o QIM; boas práticas com o QIM).

Foi nosso propósito inquirir por questionário os diretores e os professores para caracterizarmos a situação do QIM nas escolas de ensino básico no Norte de Portugal. Com o questionário usado na formação, pretendíamos recolher, informações sobre as suas expectativas em relação à formação em QIM.

Sujeitamos os nossos questionários destinados aos diretores e aos professores a uma validação de conteúdo junto de especialistas nacionais e internacionais, nas áreas da Didática, dos Métodos de Investigação e da Comunicação e Tecnologia Educativas, das Ciências da Educação e das Tecnologias da Informação e Comunicação, de instituições de ensino superior e /ou de reputados centros de investigação. As suas sugestões e recomendações em muito contribuíram para que esse instrumento se tornasse mais eficaz e claro.

O processo de validação também passou pela realização de um pré-teste, distribuindo o questionário direcionado aos diretores a 3 diretores de distritos distintos que reuniam as mesmas características da amostra, e o questionário dirigido aos professores a 122 docentes (que representam mais de $20 \%$ dos professores da amostra pretendida) com o objetivo de medir o grau de compreensão e aceitação dos mesmos. Além disso, sujeitamos os questionários a uma análise estatística para se obter um coeficiente de consistência interna também denominado por Alfa de Cronbach. Na análise de fiabilidade dos três questionários, considerando a classificação de George \& Mallery (2003: 231), pode estabelecer-se um grau de fiabilidade bom nos subconjuntos que apresentam um Alfa com valores superiores a 0,8 (Bloco III "Utilização do QIM" do questionário dos professores assim como no total deste último), um grau considerado aceitável nos valores superiores a 0,7 (Bloco II "Equipamento e disponibilidade do QIM", Bloco III "Utilização do QIM", Bloco V "Dados relativos à formação em e para o QIM" do questionário dos diretores, bem como na sua totalidade; no Bloco II "Equipamento e disponibilidade do QIM" e Bloco 
IV "Problemas/ Dificuldades e Apoio/Auxílio técnico com o QIM" do questionário dos professores e no Bloco II "Expetativas em relação à formação em QIM" do questionário diagnóstico da formação) e uma fiabilidade questionável nos valores superiores a 0,6 (Bloco IV "Problemas/ Dificuldades e Apoio/Auxílio técnico com o QIM" do questionário dos diretores e Bloco $V$ "Dados relativos à formação em e para o QIM" do questionário dos professores).

Após a fase de validação dos questionários, enviámos um pedido à Direção-Geral da Educação $(\mathrm{DGE})^{1}$ a solicitar autorização para a recolha de dados nas escolas. Fomos informados que os questionários cumpriam os requisitos da qualidade técnica e metodológica e podiam ser aplicados nas escolas desde que autorizados pelos respetivos diretores dos agrupamentos. Assim, dirigimo-nos às escolas para clarificar os objetivos do estudo, proceder à apresentação dos questionários e solicitar a aplicação dos mesmos. Nesse contacto ficou acordado se prefeririam responder em suporte papel ou em suporte digital.

Dos questionários elaborados, dois foram aplicados no início da nossa jornada no terreno (o dirigido aos diretores e o direcionado aos professores intervenientes no estudo) e um no começo da formação que ministramos (dirigido aos professores participantes na formação).

No que concerne ao questionário que criámos para a formação, todo o processo de validação ficou a cargo do centro de formação.

\subsubsection{Entrevistas}

Os métodos de entrevista, pelas suas características de proximidade entre entrevistado e investigador, permitem a obtenção de informações e elementos de reflexão muito ricos. Independentemente da estrutura da entrevista, é necessário prepará-la, o que supõe definir o objetivo, a seleção dos tópicos, a utilização de uma linguagem adequada aos entrevistados, a ordem das questões e o cuidado de não efetuar perguntas que influenciem a resposta.

Cientes das dificuldades, utilizamos um guião, não propriamente com uma listagem de perguntas, mas com os pontos mais importantes sobre os quais se pretendia ouvir os professores entrevistados. Dos vários tipos de entrevistas que existem, a que melhor se adequava aos objetivos desta investigação é a entrevista semiestruturada desenrolando-se a partir de um esquema básico, permitindo que o entrevistador faça as necessárias adaptações. As nossas entrevistas tiveram de ser realizadas telefonicamente. Durante as entrevistas, procurou-se manter o distanciamento das opiniões expressas pelos professores entrevistados, para que nunca se sentissem avaliados, com receio de não estar a responder ao solicitado ou, julgassem o seu discurso com reduzido interesse e a não corresponder às nossas expectativas.

O guião das entrevistas, elaborado de raiz, contemplava 7 grandes blocos de análise, (Identificação, Domínio do recurso, Objetivos; Descrição da Prática; Dificuldades 
Sentidas; Resultados; Perspetivas Futuras), e foi utilizado como referência e farol para o entrevistador. O guião também foi sujeito a um pré-teste a 5 professores com características semelhantes às da população-alvo, para verificar a estrutura e a clareza do roteiro. Posteriormente, foi enviado para análise e validação da DGE tal como os questionários. A realização das entrevistas foi igualmente autorizada porque após o guião ter sido submetido para análise, cumpria os requisitos. Antes da aplicação o guião tivemos em consideração as medidas de proteção e segurança previstas na Lei $n^{\circ} 67 / 98$.

As entrevistas aos professores que indicavam boas práticas com o QIM foram pensadas para obter informações mais claras e pormenorizadas quanto às suas vivências e experiências com o QIM; para aferir o modo como trabalham com este recurso; as suas expectativas face à integração deste recurso na escola e no ensino, ou seja, obter algumas informações que consideramos pertinentes e essenciais para a contextualização do nosso estudo e que possibilitassem compreender o impacto da utilização do QIM na transformação das dinâmicas pedagógicas no processo de ensino/aprendizagem dos alunos. Foram entrevistados 28 professores que evidenciaram atividades de sucesso com o QIM ou que foram indicados por algum professor como alguém que apresentava uma boa prática com o QIM.

\subsubsection{Observação de aulas}

Tendo em conta as potencialidades que a observação de aulas podia trazer para a nossa investigação, fizemos a observação de aulas aos professores que frequentaram a formação que ministramos em QIM. Assim, foram realizadas 22 sessões de observação a turmas de anos de escolaridade diversos (do $1 .^{\circ}$ ao $9 .^{\circ}$ ano de escolaridade) e em diferentes áreas disciplinares. Tratou-se de observar a utilização do QIM pelos professores e seus alunos (mediante a atividade desenhada e realizada pelos formandos), com o objetivo de verificar se as boas práticas com o QIM podem ser aprendidas com formação e recolher para disseminar boas práticas pedagógicas com o QIM. Além disso, também poderíamos observar a reação dos alunos em contexto de sala de aula e destacar a motivação intrínseca relacionada com esta ferramenta.

Fizemos uma observação participante passiva porque não nos envolvemos nos acontecimentos; fomos "outsider", podendo dessa forma apontar as ocorrências durante o período de observação. Optou-se por este tipo de observação de forma a não influenciar o decorrer dos acontecimentos, com a finalidade de descrever, o mais fidedignamente possível, os elementos observáveis.

Para essas observações, delineámos cuidadosamente uma grelha de observação, com base nos objetivos do estudo, de modo a registar factos, aspetos e acontecimentos observados durante a utilização do QIM. Desse modo, recolhemos informações sobre interesse, autonomia, curiosidade, criatividade, organização, espírito crítico entre os professores e os alunos durante a utilização do QIM para posteriormente relatar o 
mais fielmente possível os momentos observados e produzir inferências. A recolha de dados foi exclusivamente feita pelo investigador em contexto de sala de aula.

Essa grelha divide-se em 4 partes: dados de identificação da aula observada; dados relativos ao QIM na aula observada; dados relativos ao professor e ao aluno no uso do QIM e análise e reflexão sobre a observação. Após as observações, fizemos uma reflexão com o nosso ponto de vista, as nossas ideias, as nossas preocupações no momento, os nossos sentimentos, especulações, impressões, dúvidas, incertezas, surpresas e deceções.

Para sermos mais rigorosos no registo dos dados observados, elaborámos ainda uma matriz de modo a classificar os diferentes indicadores de várias questões, com base numa escala para classificação, variável entre (Insuficiente / Suficiente / Bom / Muito Bom e Não observável / Não aplicável). Assim, conseguimos ter uma orientação do que deveríamos considerar para a atribuição de uma ou outra classificação. Os itens incluídos em cada classificação foram baseados nas competências que considerámos necessárias adquirir na formação em QIM, nas fases da formação desta tecnologia e no que se deve conhecer do QIM para usar eficazmente os recursos disponíveis e favorecer o ensino/aprendizagem.

\section{Rumo ò modelo de Utilização do QIM}

Ao longo da revisão bibliográfica e de todo o nosso percurso fomos juntando várias pistas que nos levam a considerar que o QIM contempla os requisitos necessários à consecução de uma Boa Prática e consegue conduzir professores e alunos ao objetivo primeiro que uma boa prática pressupõe - a aprendizagem.

Acreditando que vivemos a "era do QIM" e que a sua utilização pode ajudar a transpor as barreiras convencionais, proporcionando um novo ambiente e a renovação na abordagem dos conteúdos, objetivos e essencialmente de métodos, propomos um modelo de utilização, estando cientes que a utilização do QIM, quer no plano do ensino quer no da aprendizagem, não significa necessariamente um cenário de inovação pedagógica. É preciso algo mais. É a pensar nesse "algo mais" que recomendamos o modelo de utilização do QIM como meio de apoio aos docentes, pois para que estas tecnologias possam ser utilizadas para atingir objetivos pedagógicos, é necessária uma estratégia de ensino / aprendizagem claramente definida, assim como a existência de alguns elementos estruturais básicos com os quais professores e alunos possam contar.

Esse modelo inclui 3 intervenientes (QIM, Aluno e Professor), abarca quinze dimensões interrelacionadas como sendo essenciais à melhoria do ensino/aprendizagem (Figura III) e pressupõe ser um mecanismo que ligue a teoria e a prática, levando à especificação de estratégias de ensino. 


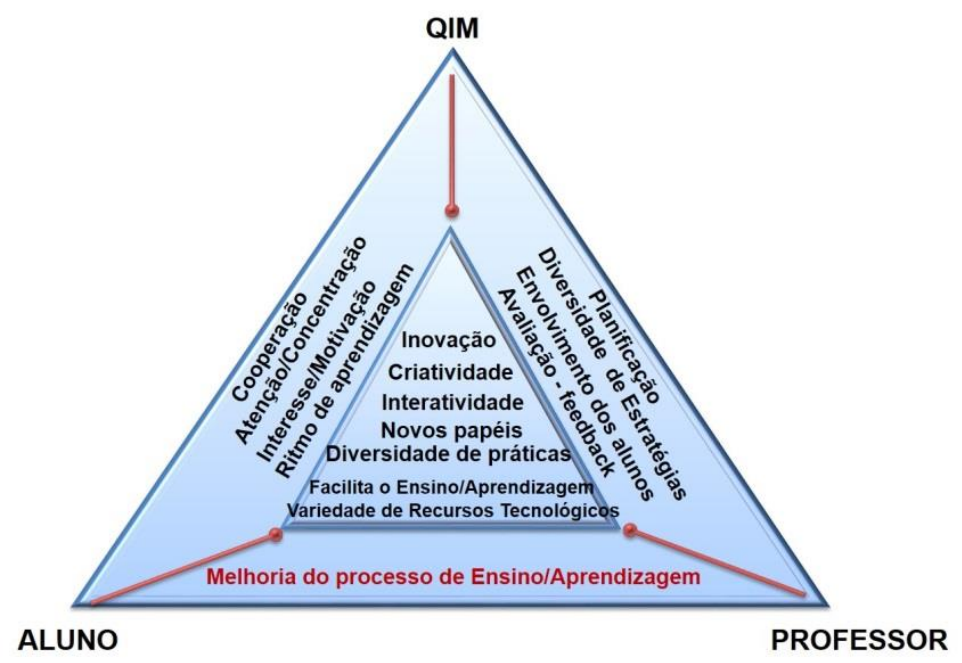

Figura III: A caminho do Modelo de utilização do QIM (Autor, 2015:423)

Portanto os três intervenientes aparecem numa relação de concordância, dependentes uns dos outros, mas cada um com papéis explícitos, claramente definidos. Nessa linha, consideramos que só há integração do QIM quando existe uma utilização regular na sala de aula, por alunos e professores, num contexto de aprendizagem ativo, real e significativo, para apoiar e melhorar a aprendizagem e o ensino.

Na relação Professor/QIM, pressupõe-se que o professor aperfeiçoe a sua capacidade de manuseamento do QIM, tirando o máximo proveito de todas as potencialidades desta tecnologia. A relação do professor com o QIM não tem de ser necessariamente, imediata; pode ser progressiva e assente numa base construtivista de aquisição de conhecimentos. Contudo, pensamos que deve atender às seguintes dimensões básicas:

- Planificação

- $\quad$ Diversidade de estratégias

- Envolvimento dos alunos

- Avaliação /Feedback

a) A dimensão da planificação revela-se de extrema importância em educação e é uma necessidade cada vez mais premente. O planeamento da matéria a lecionar numa determinada disciplina, a definição das estratégias e ferramentas que melhor se adequam aos alunos e que permitem o seu envolvimento, e as formas de avaliação/feedback são pontos basilares de 
uma planificação. Assim, devido à natureza e ação a que se refere, a planificação das aulas contemplando a utilização do QIM deve estar sujeita a um questionamento por parte do professor: Planificar para quem? Planificar para quê? Neste sentido, o professor deve prever uma planificação que permita ao aluno perceber o "fio condutor" da aula ou das aulas. Efetivamente a planificação de aulas no QIM é benéfica para o aluno e para o professor, mas também pode ser vantajosa para a escola, na medida em que pode constituir um documento de partilha de experiências e auxiliar outros docentes que sintam dificuldades em planificar as atividades incluindo o QIM como ferramenta de ensino e aprendizagem.

b) A dimensão da diversidade de estratégias de ensino é um ponto fundamental quando falamos do QIM, na medida em que as suas potencialidades permitem apostar numa diferenciação pedagógica que ajuda o aluno a adquirir e a interiorizar a informação. É importante que os professores usem variadas estratégias relativamente ao currículo, ao processo de ensino/aprendizagem e à avaliação, promovendo verdadeiras oportunidades de aprendizagem para todos os alunos na sala de aula através de ambientes diversificados. Ora, o QIM permite uma abordagem a partir de diversos elementos multimédia (texto, vídeo, áudio, imagem), mas é necessário que os docentes tenham determinados cuidados ao nível da forma, estilo de escrita, clareza e rigor científico do texto, bem como uma escolha criteriosa de imagens, vídeos e áudio, que enriqueçam o processo de ensino. Acreditamos que o professor deve diversificar as suas estratégias e o QIM é o recurso ideal para atender a essa diversificação. Ainda que o docente não saiba como organizar as suas estratégias de ensino, o importante é começar a incluir o QIM no contexto das suas aulas e progressivamente ser capaz de tornar essas aulas mais motivadoras e diferentes. As atividades propostas com o QIM devem propiciar a experiência de situações variadas, de diferentes complexidades, favorecendo assim o desenvolvimento da capacidade de lidar com situações desafiadoras. O quadro interativo é uma ferramenta que pode, de facto, ajudar os professores a criar espaços de aprendizagem entusiasmantes e seduzir crianças e jovens de todas as idades e capacidades.

c) A dimensão do envolvimento dos alunos remete-nos para uma prática pedagógica que privilegia metodologias ativas centradas no sujeito que aprende, com base em ações desencadeadas por desafios, problemas e projetos. O foco deve ser deslocado do ensinar para o aprender. O professor passa a ser facilitador e mediador do processo de aprendizagem em vez de transmissor de conhecimentos. O grande objetivo é formar alunos com autonomia e iniciativa, capazes de solucionar problemas. Com o QIM, O professor pode envolver os seus alunos em aprendizagens mais motivadoras, transmitir os conteúdos de forma diferenciada, possibilitando que os alunos retenham a informação mais facilmente e de modo mais 
atrativo. Ora, o QIM coloca ao dispor do professor um leque de ferramentas que the permite envolver os alunos nas aprendizagens. Nesta relação do professor /QIM cabe ao docente a capacidade de explorar ao máximo todas as dimensões do QIM, principalmente a dimensão da interatividade.

d) A dimensão da avaliação e do feedback objetiva avaliar um conjunto de práticas educacionais. Para isso, engloba diferentes aspetos relacionados com o ensino e a aprendizagem. A avaliação da aprendizagem envolve $a$ priori a definição de um determinado modelo de educação e dos seus pressupostos teórico-metodológicos, os quais estão implícitos na prática docente. O modelo de avaliação da aprendizagem apresenta, ou deveria apresentar, uma sintonia com o método de ensino, porque dependendo da abordagem, muda-se a conceção da natureza do conhecimento e as finalidades educacionais. O modo como o professor seleciona as formas de avaliação e os instrumentos, define os procedimentos, elabora os critérios de correção e divulgação dos resultados tem de ir ao encontro das metodologias de ensino que o QIM proporciona. Com o QIM, o feedback do professor pode ser imediato, no momento da transmissão de conteúdos, pois sendo uma ferramenta que prima pela interatividade, pode proporcionar estímulos instantâneos favorecendo assim uma forte relação entre o feedback recebido, a sua qualidade e a motivação. O QIM permite direcionar-se para uma avaliação mais formativa do que sumativa, conduzir projetos, desenvolver o trabalho em grupo, responsabilizar-se pelo aluno, recorrer a métodos ativos e ao trabalho por situações-problema e educar para a cidadania.

Na conexão Aluno/QIM, espera-se que este recurso proporcione uma atmosfera de aprendizagem apelativa, suscitando no aluno várias dimensões:

- Cooperação

- Interesse/motivação

- Atenção/concentração

- $\quad$ Diferentes ritmos de aprendizagem

a) A dimensão da cooperação na relação Aluno/QIM remete-nos para uma aprendizagem que implica a cooperação dos alunos no processo de aprendizagem. Entendemos que o QIM pode proporcionar a cooperação entre os alunos, favorecendo o rendimento e a produtividade, assim como facilitar a memória a longo prazo, a motivação intrínseca, a atenção e o pensamento crítico. A cooperação entre os alunos permite ainda a criação de ideias e soluções novas, levando a uma transformação mais significativa do que se está a aprender. Com esta tecnologia o aluno torna-se mais 
autónomo e consequentemente assume a responsabilidade própria para tomar decisões no desenrolar das tarefas. Nesta perspetiva, aprender é algo mais do que aceder e reproduzir um conjunto de termos e conceitos transmitidos pelo professor, em que o aluno não reconhece qualquer importância para o seu dia-a-dia. O QIM estimula a iniciativa, a atenção aos pormenores e o empenho na atividade, a ajuda entre alunos, em que os mais capazes podem facilitar a aprendizagem dos mais fracos sem com isso saírem prejudicados e permite que o aluno coopere para aprender.

b) A dimensão do interesse e motivação dos alunos com o QIM prima pela quantidade de informação que este recurso pode trazer para a sala de aula, motivando os alunos para a aprendizagem. De facto, o QIM pode operar uma mudança ao trazer para a sala de aula recursos e informação que, de outra forma, seria quase impossível de conseguir. Referimo-nos ao facto de se poder fazer uma visita guiada, por exemplo, a um museu ou a uma cidade. O contacto, embora virtual, com essas realidades permite alimentar a discussão, a construção de conhecimento e favorece a interação entre os alunos e entre os alunos e o professor e essa interatividade motiva os alunos. Entendemos que o QIM faculta a todos os alunos a possibilidade de terem ao seu dispor a informação, permitindo recolher, selecionar, ordenar, gerir e utilizar essa mesma informação tornando-os implícitos no conceito de construção da aprendizagem. O uso das ferramentas e recursos do QIM, de outro software ou ainda o acesso à Internet que esta tecnologia oferece, são fatores que melhoram o interesse, a motivação e a compreensão dos alunos.

c) A dimensão da atenção/concentração é importante nesta dinâmica Aluno/QIM pois a utilização do QIM consegue captar o interesse do aluno e a atenção nos momentos de ensino por mais tempo. Na verdade, a utilização do quadro interativo tem impacto positivo na atenção, concentração e atitude de todos os alunos.

d) A dimensão dos diferentes ritmos de aprendizagem merece ser destacada, na medida em que a escola atual deve reconhecer e satisfazer as diversas necessidades dos alunos, adaptando-se aos diferentes ritmos de aprendizagem, às experiências e à inter-relação da criança com o meio, através de adaptações curriculares, de estratégias pedagógicas diversificadas e de uma boa organização escolar. Podem considerar-se os diferentes ritmos de aprendizagem dos alunos, porque os professores têm a possibilidade de recorrer a muitas e variadas fontes e recursos para responder às necessidades específicas dos alunos. O QIM, como instrumento de educação de crianças e adolescentes, oferece uma oportunidade sem precedentes de responder com toda a qualidade necessária a uma procura cada vez mais intensa e diversificada. As possibilidades evantagens que apresenta no campo pedagógico são 
consideráveis já que permite que todos, independentemente dos seus ritmos de aprendizagem, construam as suas aprendizagens.

Na relação Aluno/Professor, acreditamos que com a utilização do QIM na sala de aula se verifica uma alteração dessa relação. Dado que o substituto do quadro preto abre as "janelas" para a motivação, novas metodologias de ensino e aprendizagem, novas dinâmicas de sala de aula, pensamos que a relação entre professor (ensino) e aluno (aprendizagem) ganha com a utilização do QIM no contexto educativo. A relação entre professores e alunos pode agora ser mais virada para uma dinâmica de colaboração e interajuda. A educação autêntica não se faz sem a participação genuína do aluno, nem se faz transmitindo informação do professor para o aluno ou do aluno para o professor, mas na interação de professores e alunos.

Se relacionarmos os 3 intervenientes, abrimos a sala de aula para a inovação, variedade de recursos tecnológicos (importantes no desenvolvimento de capacidades para atuar no mundo de hoje) e para a interatividade, provocando outra criatividade, novos papéis e diversidade de práticas, facilitando assim o ensino e a aprendizagem.

Estamos conscientes de que os principais atores do contexto educativo são os alunos e os professores, e de que o desenvolvimento de modelos pedagógicos deve ter em conta estes atores, o contexto de ensino e aprendizagem e os meios disponíveis. Acreditamos que não sendo o QIM um elixir nem uma fórmula mágica, pode melhorar o ensino e a aprendizagem e pode proporcionar uma Boa Prática de ensino, pois permite que a aula se desenvolva com os 3 intervenientes (professor, aluno e o recurso QIM).

Neste modelo, o QIM desempenha um papel central na mudança do processo de ensino/aprendizagem, facilitado pelas novas formas de ensinar e de aprender que o recurso a esta tecnologia potencia. Permite a criação de ambientes de aprendizagem mais ricos, onde os alunos têm um papel mais ativo na construção do seu conhecimento. É fácil de usar, melhora rapidamente o ensino e a aprendizagem e potencia a criatividade. $O$ processo deixa de se centrar no professor, que era o transmissor exclusivo dos saberes, e passa a centrar-se mais no aluno, tornando-se mais companheiro de caminho, um orientador pedagógico, tecnológico e motivacional, dotando os alunos de maior autonomia e mais responsabilidades sobre as suas aprendizagens. $O$ conceito de ensino passa a estar mais centrado no processo e não no produto final.

Nesse modelo, professores e alunos têm de estar recetivos às novas tecnologias e deverão ser capazes de se adaptar à mudança, aceitando o novo papel que lhes é atribuído. Para que haja um efeito no processo de conhecimento dos alunos, não basta apenas a existência do recurso didático (QIM); é preciso que haja uma efetiva utilização pelos professores e que os alunos lhe tenham acesso. Para se retirar proveito do QIM, é preciso colocá-lo ao serviço de um projeto educativo renovado, 
em que para além daquilo que se aprende, se aprende a aprender, onde o professor se assume como agente crucial de mudança. É preciso estar recetivo à mudança. Por isso é que a mudança de práticas tem sido um processo lento e moroso.

Não pretendemos acabar com as práticas educativas mais tradicionais assentes em métodos expositivos de transmissão dos conhecimentos e no trabalho individual dos alunos, porque haverá alunos que ainda se revejam nessas práticas, mas aspiramos a que efetivamente outras práticas aconteçam na sala de aula centradas no aluno e envolvendo-o em experiências de trabalho colaborativo. Podemos melhorar as práticas tradicionais e proporcionar outros ambientes, porque a mudança que está a ocorrer representa uma transformação de paradigma onde surgem novas necessidades e novas possibilidades.

\section{Referências Bibliográficas}

António, A. A. T. J. (2011). A Utilização dos QIM no Ensino da Matemática - Contributo para a melhoria das aprendizagens (Dissertação de Mestrado). Vila Real: Universidade de Trás-os-Montes e Alto Douro.

Antunes, P. M. B. (2008). Impacte dos quadros interactivos nas práticas docentes: um estudo de caso (Dissertação de Mestrado). Aveiro: Universidade de Aveiro.

Batista, T. M. F. (2009). Impacte dos Quadros Interactivos nas Escolas do Concelho de Oliveira do Hospital (Dissertação de Mestrado). Aveiro: Universidade de Aveiro.

Corrente, A. C. C. (2009). O Quadro Interactivo no Ensino da Matemática. Analisando o trabalho de dois professores em contexto de colaboração. (Dissertação de Mestrado). Évora: Universidade de Évora.

Esteves, J.; Lencastre, J. (2013). Criação de Recursos Didáticos para Quadros Interativos Multimédia. Atas do XII Congresso Internacional Galego- Português de Psicopedagogia (CD-Rom): Braga, pp. 6459-6474.

Fernandes, M. G. (2009). Impacto Dos Quadros Multimédia Interactivos Nos Contextos de Aprendizagem (Dissertação de Mestrado). Lisboa: Universidade Católica Portuguesa.

Ferreira, A. P. (2011). Utilização dos Quadros Interativos Multimédia em contexto educativo: estudo de caso numa escola do Ensino Básico. (Dissertação de Mestrado). Bragança: Escola Superior de Educação de Bragança.

Ferreira, C. F. (2010). O uso do QIM nas aulas de língua estrangeira como elemento motivador. (Dissertação de Mestrado). Porto: Universidade do Porto.

Ferreira, P. M. P. G. (2009). Quadros interactivos: novas ferramentas, novas pedagogias, novas aprendizagens. (Dissertação de Mestrado). Braga: Universidade do Minho.

Flick, U. (2004). Uma introdução à pesquisa qualitativa. Porto Alegre: Bookman. 
Folhas, R. C. R. L. (2010). Formação de professores de ciências sobre Quadros Interactivos em regime de bLearning (Dissertação de Mestrado). Aveiro: Universidade de Aveiro.

Fortin, M.F. (1999). O Processo de Investigação - da concepção à realização. Décarie Éditeur, Lusociência.

Freire, Po. (1996). Pedagogia da Autonomia: Saberes Necessários à Prática Educativa. Rio de Janeiro: Paz e terra.

George, D.; Mallery, P. (2003). Spss for Windows step by step: A simple guide and reference. 11.0 Update (4. ${ }^{\text {a }}$ ed.). Boston: Allyn \& Bacon.

Ilharco, F. (2004). A Questão Tecnológica - Ensaio sobre a Sociedade Tecnológica Contemporânea, Lisboa: Principia.

Lopes, N.; Escola, J.; Raposo-Rivas, M. (2013). Quadro Interativo Multimédia: A Nova Janela para a Aprendizagem no Ensino em Portugal. Atas do XII Congresso Internacional Galego- Português de Psicopedagogia (CD ROM): Braga, pp. 6482-6497.

Lopes, N.; Escola, J.; Raposo-Rivas, M. (2014). Estado da arte do uso do QIM em Portugal: aproximação a um campo de estudo emergente. In J.J.J. Escola, M. RaposoRivas, M.E. Martínez-Figueira, A.P.F. Aires (coord.), Rumo à inclusão educacional e integração das TIC na sala de aula (pp.357-382). Santiago: Andavira.

Lopes, N. (2015). Quadro Interativo Multimédia: A Nova Janela para a aprendizagem no Ensino Básico - presença, usos e metodologias no Norte de Portugal (Tese de Doutoramento). Vila Real: Universidade de Trás-os-Montes e Alto Douro.

Martins, J. A. S. (2012). O Quadro Interativo Multimédia em contexto de ensino/aprendizagem: um estudo de caso com uma turma do $4 .^{\circ}$ ano (Dissertação de Mestrado). Lisboa: Universidade Católica Portuguesa.

Marques, V. L. M. (2009). Os Quadros Interativos no ensino da Matemática (Dissertação de Mestrado). Porto: Universidade Portucalense Infante D. Henrique.

Pardal, L.A.; Correia, E. (1995). Métodos e técnicas de investigação social. Lisboa: Areal Editores.

Plano Tecnológico -PTE- (2007). Uma Estratégia de crescimento com base no Conhecimento, Tecnologia e Inovação. Disponível em http://wwwplanotecnologico.pt.

Pereira, A. S. D. C. A. (2008). Integração dos quadros interactivos multimédia em contexto educativo. Um estudo de impacte numa escola de Leiria (Dissertação de Mestrado). Aveiro: Universidade de Aveiro.

Prensky, M. (2009). Digital natives, digital immigrants. In the Horizon, vol.9, n5.

Quivy, R.; Campenhoudt, V. (2003). Manual de investigação em ciências sociais. Lisboa: Gradiva. 
Spínola, T. M. G. (2009). A utilização do quadro interactivo multimédia em contexto de ensino e aprendizagem Impacte do projecto "O Quadro interactivo multimédia na RAM" (Dissertação de Mestrado). Aveiro: Universidade de Aveiro.

Tuckman, B. W. (2000). Manual de investigação em educação: como conceber e realizar o processo de investigação em educação. Lisboa: Fundação Calouste Gulbenkian.

Vasconcelos, T.; Moreira, J. (2013). Avaliação da Usabilidade do QIMTERATIVO de Português testes realizados. Atas do XII Congresso Internacional Galego- Português de Psicopedagogia (CD-Rom): Braga, pp. 6442-6458.

\section{Notas}

1 Os pedidos de autorização para aplicação de inquéritos/realização de estudos de investigação, em meio escolar, deverão ser submetidos em http://mime.gepe.minedu.pt, para apreciação da DGE, através do sistema de Monitorização de Inquéritos em Meio Escolar (MIME), concebido especificamente para esse fim. 